\title{
MICROORGANISMS AS CHEMICAL FACTORIES FOR ISOLATION OF META-BOLOMES FROM MESOPHILIC SOIL
}

\author{
ABHISHEK SHARMA, EKTA MENGHANI* \\ Department of Biotechnology, JECRC University, Vidhani Village, Ramchandrapura, Near Mahatma Gandhi Hospital, Jaipur 303905 \\ Email: ekta.menghani@jecrcu.edu.in
}

Received: 16 Oct 2016 Revised and Accepted: 27 Feb 2017

\begin{abstract}
Objective: To investigate the micro-flora of the mesophilic soil of Rajasthan for isolation of novel compounds having antibacterial potentials.
\end{abstract}

Methods: In present experiments, bacterial colonies were isolated from four different regions of Jaipur, Rajasthan and screened for antimicrobial efficacy against five selected pathogens Pseudomonas aeruginosa MTCC 7093, Staphylococcus aureus MTCC 7443, Escherichia coli MTCC 40, Klebsiella pneumoniae MTCC 530, and Bacillus subtillis MTCC 121. Antimicrobial efficacy against the selected strains was performed. The potential efficacy of the extract was also screened for gas chromatography-mass spectroscopy (GC-MS) analysis for novel metabolites screening. Further, potent bacterial strains were identified at the molecular level by $16 \mathrm{~S}$ ribosomal deoxyribonucleic acid (DNA) sequencing method.

Results: After the primary screening, 29 microbial isolates were selected for the screening of bioactivity. Results displayed zones of inhibition ranging from $5 \mathrm{~mm}$ till maximum $13 \mathrm{~mm}$. Soil testing indicated survival conditions for microbes isolated, and biochemical tests supported the identification of screened isolates. The potentially isolated strains S-III C, S-III D and S-IV D were identified at the molecular level using 16S ribosomal DNA sequencing as Bacillus shackletonii, Bacillus thuringiensis and Bacillus subtilis subsp. inaquosorum, respectively.

Conclusion: Extraction of active metabolites from soil microbiota, against five pathogenic bacteria, is far better, safe and economical method. This study will help in exploring new compounds against increasing number of resistant pathogenic strains with an aim to reduce demand of medicinal plants for extraction of effective antimicrobial compounds. Bacillus strains (S-IIIC, S-IIID and S-IVC) isolated from soil microflora possess antimicrobial activity and can be used for isolation of antibiotics at industrial levels.

Keywords: Microorganisms, Chemical factories, Metabolomes, Mesophilic

(C) 2017 The Authors. Published by Innovare Academic Sciences Pvt Ltd. This is an open access article under the CC BY license (http://creativecommons.org/licenses/by/4. 0/) DOI: http://dx.doi.org/10.22159/ijpps.2017v9i4.15708

\section{INTRODUCTION}

In India, the most common pathogens behind nosocomial infections are the gram-positive bacteria, with Staphylococcus aureus being the principal one. There has been a raise in the rate of antibiotic resistance in bacteria related to nosocomial infections, most importantly in intensive care units. These are nowadays the prominent sites of infections. There are many broad-spectrum antibiotics, such as vancomycin, which are usually given for treating such infections. However, there have been cases of vancomycinresistant enterococci and vancomycin-resistant Staphylococcus aureus being reported. This leads to use of alternate antibiotics and prevents the use of vancomycin as the primary drug for the treatment of diarrhea caused by Clostridium difficile [1].

There are different categories of microorganisms causing nosocomial infections, and the pathogen vary according to the group of people being infected, kinds of health care settings, medical facilities, and also the countries (developed and developing). Commonly reported gram positive microbes include Staphylococcus aureus, Staphylococci coagulase negative, and Enterococci. Gramnegative ones include Acinobacter baumanii, Klebsiella pneumoniae, Escherichia coli, and Pseudomonas aeruginosa [2-4]. Fungi are also recognized as a cause of nosocomial infections, mainly in blood streams, apart from bacterial infections in India [5].

Natural products are described in simple terms as those chemical matter isolated from different kinds of living beings. These could be classified on a broad basis as primary or secondary. It has been the most suspicious field of microbiology to conclude a precise definition, describe exact functions and existence of secondary mentabolites (SMs) in nature [6]. SMs are low molecular weight compounds (usually less that 3000) with diverse and complicated chemical configurations, incomprehensible functions, produced by strains of distinct microbial species, and by some plants. Although antibiotics are the best known bioactive metabolites, there are many more with significant activities of medical, nutritional and industrial importance [7]. They seem to be completely unnecessary for the microbial producers, having no any noticeable function in their life cycle, but they help in the survival of the microbial population in adverse conditions [6]. The function of SMs is opposite to that of primary metabolites, like nucleic acids, proteins, fats and carbohydrates, which are essential for microbial growth. Though the process of secondary metabolite production is based on genes, but these are highly influenced by changes in the environment of the microorganism. Apart from nutrient deficiency, other factors could be declining growth rate and the presence of inducer [8]. These factors tend to generate signals that cause a cascade of events leading to morphological and chemical changes in the microbial strains. It is considered that the cell investment in secondary metabolite production is almost the confirmation of a function that should give the organisms certain advantage against other members of the community. These are produced by the organisms to inhibit other organism's competing for a same ecological niche. Also, they are produced after active growth of the organism and are structurally diversified. The distribution of SMs is also unique, and some metabolites are found in a range of related microorganisms, while others are only found in one or a few species. Parallel to the screening for new antibiotics, efforts have been focused in finding low molecular weight SMs with different biological activities [9-12].

The SMs isolated from microbes exhibits either antimicrobial; which includes antibacterial, antifungal, anti-protozoan action; antitumor or antiviral activities, earlier known as antibiotics. With the aid of recent knowledge, the term "antibiotic" is more or less an obsolete conception, whenever there is discussion regarding the bioactive SMs. The practical importance of antibiotics and other SMs is incredible. They have wide applications in the human therapy and veterinary therapy, agriculture, scientific research and in numerous other areas. 
Antibacterial substances produced by Bacillus species to be found on the second place after laboratory due to variety in the antimicrobial peptide (AMP) due to different chemical structures [13]. The Bacillus subgroup has been reported to produce a huge number of amplifiers, and this can be a good source to explore the novel antibacterial substances $[14,15]$. Compounds extracted have been shown to be active against a broad range of gram-positive bacteria [16]. An amount of reported bacteriocins is very less as in comparison to the reported microbial species, so necessitating a need to explore the properties and therapeutic applications of microorganisms such as Bacillus. The aim of the current research was going to target the bacteria producing anti-bacterial substance from the mesophilic soil. The soil is a rich source of microorganisms, as it offers an optimum environment for the growth of microorganisms, which contributes towards tremendous diversity of bacteria. In the current study, we have isolated different microorganisms which are able to produce antimicrobial substances from the soil of the arid and semi-arid region, sterile techniques and required plating methods. The significant microbes were further determined by molecular characterization.

\section{MATERIALS AND METHODS}

\section{Chemicals used}

The chemicals and media utilised in the current study were bought from Hi-Media, CDH, SRL and Sigma-Aldrich.

\section{Methods}

\section{Test pathogens and growth conditions}

Pure cultures of five test pathogens were obtained from Department of Microbiology, JECRC University, Jaipur and SMS hospital. These included Pseudomonas aeruginosa MTCC 7093, Staphylococcus aureus MTCC 7443, Escherichia coli MTCC 40, Klebsiella pneumoniae MTCC 530, and Bacillus subtillis MTCC 121. These test pathogens were cultured in nutrient broth at $36{ }^{\circ} \mathrm{C}$ for 16-18 h. Microbial isolates were tested against these five bacteria using disc diffusion, well diffusion and perpendicular cross streak methods $[17,18]$.

\section{Isolation of antibacterial compounds producing bacteria from mesophilic soil}

Bacterial strains were isolated from soil collected from four locations of Jaipur, Rajasthan i.e. slum area of Jawahar circle, SMS hospital, Durgapura and Mansarovar, and listed in table 1. Selection of site was also based on various factors, like the temperature of the particular area, population load around the area, the presence of any organic or inorganic additive/contaminant to the soil of the particular region, ease of repetition of sample collection, and ease of accessibility of the area. Soil was collected from $0.04 \mathrm{~m}$ deep from the top soil layer, ateach of these locations. It was then brought to the laboratories and stored at $4{ }^{\circ} \mathrm{C}$ till further processing.

Suspension of all the four soil samples was prepared using physiological methods and followed by serial dilution method. Spread plate technique on nutrient agar plates was used for the isolation of microorganisms. Serial tenfold dilution of mesophilic soil samples were spread on sterile nutrient agar plates and incubated at $36^{\circ} \mathrm{C}$ for $24 \mathrm{~h}$. Total 29 isolates were obtained out of which only six were morphologically dominant which were selected for further study. Nutrient agar ( $5 \mathrm{~g} / \mathrm{l}$ peptone; $3 \mathrm{~g} / \mathrm{l}$ beef extract; $5 \mathrm{~g} / \mathrm{l} \mathrm{NaCl} ; 15$ $\mathrm{g} / \mathrm{l}$ agar) was prepared and autoclaved for plating the soil samples using warcup method and direct soil sprinkle method. After 24-36 h of incubation at $35{ }^{\circ} \mathrm{C}$ and $40{ }^{\circ} \mathrm{C}$ plates were observed for screening the required colonies [19].

\section{Upscaling of culture}

The colonies screened from the dilutions of soil samples were inoculated in Luria broth media. Shaker treatment for $2 \mathrm{~h}$ daily at $700 \mathrm{rpm}$ was provided for $30 \mathrm{~d}$ at different temperature ranges. Regular testing of metabolites (primary/secondary) was done after $7 \mathrm{~d}, 15 \mathrm{~d}, 21 \mathrm{~d}$, and $27 \mathrm{~d}$ [20].

\section{Liquid-liquid extraction of bioactive compounds}

After $27 \mathrm{~d}$ of incubation, each culture was centrifuged at $8000 \mathrm{rpm}$ for $10 \mathrm{~min}$ and the supernatant was collected separately. Metabolites were extracted using three solvents i.e. benzene, ethyl acetate and chloroform. The supernatant was mixed in 2:1 ratio with each of the three solvents, shaken and allowed to mix properly. The mixture was left undisturbed to allow the separation of the solvent is having the dissolved metabolites from the culture. The solvent was then decanted from the culture and allowed to vaporize at $40-50{ }^{\circ} \mathrm{C}$ in the oven. The method used for separating bioactive compounds from extracellular SMs was liquid-liquid extraction. Further, these extractives were named as LLE-I, LLE-II and LLE-III for benzene, ethyl acetate and chloroform respectively [21].

\section{Analysis of biological activity}

The dried form of compounds collected was again mixed in 2-3 ml of respective solvents. Sterilized circular discs were cut and soaked in solvents containing bioactive compounds. Lawn of five common nosocomial infection causing pathogens i.e. Staphylococcus aureus, Klebsiella pneumonia, Bacillus subtilis, Pseudomonas aeruginosa and Escherichia coli was prepared on nutrient agar, and all are nomenclature in table 2 . The antimicrobial activity was then tested against these pathogens using disc diffusion method [22]. Plates were incubated at $38^{\circ} \mathrm{C}$ for $48 \mathrm{~h}$.

\section{Segmentation and categorization of biologically active compounds}

\section{Centrifugation}

Centrifugation of culture broth was performed at $8000 \mathrm{rpm}$ for 10 min. Supernatants of S-III C, S-III D and S-IV C were collected for liquid-liquid extraction with benzene, ethyl acetate and chloroform as LLE I, LLE II and LLE III, respectively, and processed for antimicrobial screening. Three bio-actively rich fractions were collected and stored at $4^{\circ} \mathrm{C}$ for further studies.

\section{Thin layer chromatography (TLC)}

Glass plates of $18 \mathrm{~cm} \times 18 \mathrm{~cm}$ were used to perform TLC, so that approximately 4 samples could be run together. The slurry was made with silica gel and water. Mixing and shaking of silica gel in water should be proper for the homogenous and adhesive mixture. Thin layer on glass plates was formed and kept for $3-4 \mathrm{~h}$ on the plain surface for drying and later in the oven at $70{ }^{\circ} \mathrm{C}$. The temperature of the oven was raised to $110^{\circ} \mathrm{C}$ for $1 \mathrm{~h}$ for activation of the plates. The plates were taken out and allowed to cool. Mobile phase (solvent) was prepared and poured in TLC glass chamber in which plates spotted with extract were placed. The plates were placed in the chamber till it run or develop up to $3 / 4$ of the TLC plate and then again kept in oven for drying. Plates were sprayed with specific reagents and spots were observed. The developed plate was baked at $110^{\circ} \mathrm{C}$ for $30 \mathrm{~min}$ and observed under UV light chamber and the displacement of development (mobile phase) and extract were measured and recorded [23].

\section{GC-MS analysis}

Shimadzu model QP-2010 plus, column-Rtx-Ms, 30 meter $\times 0.25 \mathrm{~mm}$ i.d. $\times 0.25$ um film thickness was used for detection. Samples were prepared accordingly for analysis. Extracts were collected in $100 \mathrm{ml}$ beaker and mixed with methanol. The mixture was filtered properly to remove any crystal particle. The homogenous solution was collected in ependrof after testing it with microinjection. Samples were loaded in the injector and processed. Chromatograms with compounds detected in solvent were recorded and compared compound library [24].

\section{Microbial identification}

The bacterial samples (S-III C, S-III D and S-IV C) were sent for identification based on 16SrRNA analysis and the recorded in table 8-10. The identification report was generated using EZ-Taxon Database and the confidence in identification is limited by both the availability and the extent of homology shown by the $\sim 1200 \mathrm{bp}$ sequence of the sample with its closest neighbor in the database. Details and sequence fasta are shown in fig. 3 [25]. 
Bacterial genomic DNA was isolated using the Insta Gene TM Matrix Genomic DNA isolation kit as per the kit instruction procedures. An isolated bacterial colony was picked and suspend in $1 \mathrm{ml}$ sterile water in a microfuge tube, centrifuged for 1 minute at 10,000-12,000 rpm to remove the supernatant. Around $200 \mu \mathrm{l}$ of Insta Gene matrix was added to the pellet and incubated at $56{ }^{\circ} \mathrm{C}$ for $15 \mathrm{~min}$, rotated at high speed for 10 seconds, and placed in a $100{ }^{\circ} \mathrm{C}$ heat blocker boiling water bath for $8 \mathrm{~min}$. Finally, the content was rotated at high speed for 10 seconds and spanned at 10,000-12,000 rpm for $2 \mathrm{~min}$. In result, $20 \mu \mathrm{l}$ of the supernatant was used per $50 \mu \mathrm{l}$ PCR reaction.

\section{RESULTS AND DISCUSSION}

\section{Bacterial strains isolation}

Four locations were selected from the vicinity of Jaipur slum area of Jawahar circle, SMS hospital, Durgapura and Mansarovar, identity number given to the particular location is S-I, S-II, S-III and S-IV respectively. The locations were selected on the basis of the quality of the soil. These areas are rich in contamination as hospitals are the prime locations and sites for the various infections and slum areas are the power plants for the same. Further, the locations are of the arid region. Samples were collected in sterile bags and 29 colonies were isolated from all the four areas were shown in table 1 . These colonies were subcategorized into A, B, C, and D etc for systemic nomenclature. These colonies were collected by various streaking methods viz. warcup method and direct soil sprinkle method onto nutrient agar media.

These 29 colonies were further sub-cultured to isolate as pure colonies and used for future testing. To start with the target was to discover the organisms having a resistive action against a few pathogens and also for nosocomial infection-causing pathogens. 29 isolates were processed through various test techniques against selected 5 test pathogens i.e. E. coli, Bacillus subtilis, Pseudomonas aeruginosa, Klebsiella pneumonia and Staphylococcus aureus. The test pathogens which were used are listed with MTCC code in table 2.

Table 1: Screened microbial isolates

\begin{tabular}{llll}
\hline Soil sampling location & Soil sample I.D. & Total no. of bacterial isolates & Isolate I.D. \\
\hline JC slum area & S-I & 7 & A,B,C,D,E,F,G \\
SMS hospital & S-II & 8 & A,B,C,D,E,F,G,H \\
Durgapura & S-III & 7 & A,B,C,D,E,F,G \\
Mansarover & S-IV & 7 & A,B,C,D,E,F,G \\
\hline
\end{tabular}

Table 2: List of test pathogens

\begin{tabular}{lll}
\hline Soil sampling location & Soil sample I.D. & Total no. of bacterial isolates \\
\hline Pseudomonas aeruginosa & MTCC 7093 & P1 \\
Staphylococcus aureus & MTCC 7443 & P2 \\
Escherichia coli & MTCC 40 & P3 \\
Klebsiella pneumonia & MTCC 530 & P4 \\
Bacillus subtilis & MTCC 121 & P5 \\
\hline
\end{tabular}

This limited down the search for extraction of a compound of fundamental significance. Out of 29 isolates, 3 indicated biological action against previously mentioned 5 test pathogens were listed in table 2 and shown in fig. 1 . Whereas table 3 clearly shows the size zone of inhibition in millimeter and conclusive data was interpreted by mean deviation.

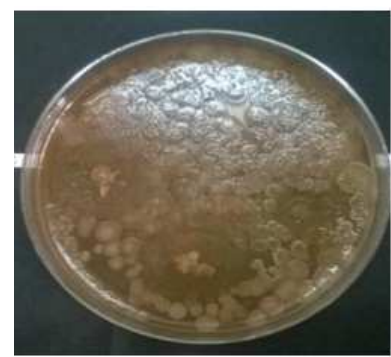

A

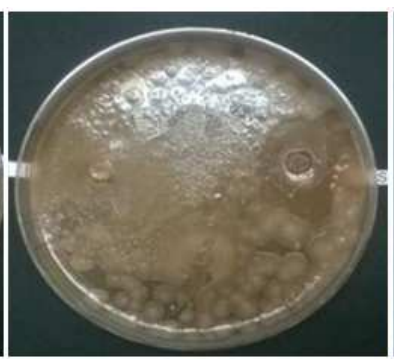

B

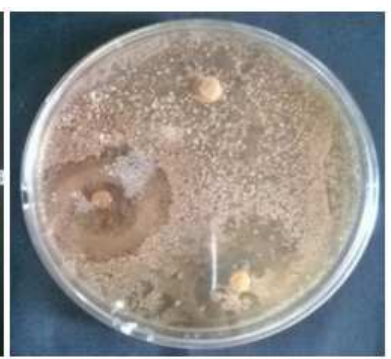

C

Fig. 1: Antimicrobial screening plates showing positive results, A=S-III C against Pseudomonsa aeruginosa, B=S-III D against, Staphylococcus aureus, C=S-IV D against Escherichia coli

Table 3: Antimicrobial analysis of strains (S-IIIC, S-IIID and S-IV C) against five test pathogens i.e. P1, P2, P3, P4 and P5

\begin{tabular}{|c|c|c|c|c|c|c|}
\hline \multirow{3}{*}{\multicolumn{2}{|c|}{ Identification of Isolates shown antibiotic activity }} & \multicolumn{5}{|c|}{ Zone of inhibition (mm) } \\
\hline & & \multicolumn{5}{|c|}{ Test pathogens } \\
\hline & & P1 & $\mathbf{P 2}$ & P3 & P4 & P5 \\
\hline \multirow[t]{3}{*}{ Soil samples } & S-III C & $13 \pm 0.20$ & 0 & 0 & 0 & 0 \\
\hline & S-III D & 0 & 0 & $9 \pm 0.20$ & 0 & 0 \\
\hline & S-IV C & 0 & $10 \pm 0.3$ & 0 & 0 & 0 \\
\hline
\end{tabular}

Values are mean Inhibition zone $(\mathrm{mm}) \pm \mathrm{SD}$ of quadruplicate, P1-Pseudomonas aeruginosa; P2-Staphylococcus aureus; P3-E. coli; P4-Klebsilla pneumonia and P5-Bacillus subtilis

For further screening, these 3 isolates were prepared through maturation handle with standard shaker treatment for a particular span and diverse incubation period and temperature. Centrifugation took after by extraction with solvents LLE-I, LLE-II and LLE-III 
separately. Activity test is necessary for affirming which fraction is really producing SMs or compounds and under what conditions it is in charge of the movement against the test pathogens are tabulated in table 4.

Table 4: Extracts from liquid-liquid extraction method $(\mathrm{g} / 100 \mathrm{ml})$

\begin{tabular}{llll}
\hline Extracts sample & Benzene & Ethyl acetate & Chloroform \\
\cline { 2 - 4 } & Extract/100 $\mathbf{~ m l}$ & & 0.02 \\
S-III C & 0.07 & 0.06 & 0.05 \\
S-III D & 0.19 & 0.04 & 0.16 \\
S-IV C & 0.16 & 0.15 & 0.15 \\
\hline
\end{tabular}

Tests and above-mentioned experiments confirmed that the isolates S-III C, S-III D and S-IV C are producing the compounds which need to be targeted. For detailed information about the compounds, they were processed through TLC with $\mathrm{R}_{\mathrm{f}}$ value mentioned in table 5 .

Table 5: $\mathbf{R}_{\mathrm{f}}$ values and color of spot from TLC analysis

\begin{tabular}{llllll}
\hline Isolates & $\mathbf{R}_{\mathbf{f}}$ Value & & \multicolumn{3}{c}{ Color of spot } \\
\cline { 2 - 6 } & Benzene & E. A. & Chloroform & Benzene & E. A. \\
\hline S-III C & - & 0.3 & - & - & Dark brown \\
S-III D & 0.5 & 0.15 & - & N. D. & Dark orange \\
S-IV C & - & - & 0.11 & - & - \\
\hline
\end{tabular}

Disengagement, determination and biochemical testing was accomplished for the essential screening of microorganisms and enlisted in table 6 and 7. Principle target was to detach a microorganism which produces a compound which can be valuable in assembling drug against nosocomial disease bringing on pathogens.

Table 6: Results of biochemical tests of screened isolates

\begin{tabular}{lllllllll}
\hline $\begin{array}{l}\text { Sample } \\
\text { location }\end{array}$ & $\begin{array}{l}\text { Catalase } \\
\text { test }\end{array}$ & $\begin{array}{l}\text { Of basal } \\
\text { test }\end{array}$ & $\begin{array}{l}\text { SIM } \\
\text { test }\end{array}$ & $\begin{array}{l}\text { Mac conkey } \\
\text { test }\end{array}$ & $\begin{array}{l}\text { Starch } \\
\text { hydrolysis }\end{array}$ & $\begin{array}{l}\text { Motility } \\
\text { Mannitol }\end{array}$ & $\begin{array}{l}\text { Urease } \\
\text { test }\end{array}$ & $\begin{array}{l}\text { Tentative } \\
\text { microbe }\end{array}$ \\
\hline S-III & C & + & - & Red & - & + & + & - \\
S-III & D & + & - & - & + & - & - & - \\
S-IV & C & + & + & Red & - & + & - & - \\
\hline
\end{tabular}

Table 7: Microscopic and morphological studies of screened colonies

\begin{tabular}{|c|c|c|c|c|c|c|c|c|}
\hline \multicolumn{2}{|c|}{ Sample location } & Shape & Color & Opacity & Elevation & Surface & Texture & Gram+ve/-ve \\
\hline S-III & $\mathrm{C}$ & Rods & Buff & Opaque & Curve & Smooth & Butyrous & negative \\
\hline S-III & D & Rods & yellow & Opaque & Negligible & Smooth & Butyrous & negative \\
\hline S-IV & $\mathrm{C}$ & Rods & Buff & Translucent & Negligible & Smooth & Viscid & negative \\
\hline
\end{tabular}

Applications and medical significance of every compound were analyzed. Isolates which showed biological activities against nosocomial infection causing pathogens were tested for biochemical as well as their morphological features. After the primary and secondary screening, these isolates were analyzed for 16s RNA sequences for the comprehensive identification and genome sequencing was reported in table 8-10. The results proved that the identified nucleotide sequences were having great similarities to the Bacillus species, which confirms the production of antibacterial compounds by culturing and processing confirmed microorganism.

Table 8: List of the closely related strains for sample S-III C

\begin{tabular}{|c|c|c|c|c|c|}
\hline S. No. & Name of strain & Code & Accession no. & Pairwise similarity \% & Reference \\
\hline 1 & Bacillus sonorensis & ATCC 14579(T) & AE016877 & 99.21 & {$[26]$} \\
\hline 2 & Bacillus aureus & ATCC $14578(\mathrm{~T})$ & AB190217 & 99.11 & [27] \\
\hline 3 & Bacillus tequilensis & - & AE016879 & 99.12 & [27] \\
\hline 4 & Bacillus thuringiensis & ATCC $10792(\mathrm{~T})$ & ACNF01000156 & 98.84 & [28] \\
\hline 5 & Bacillus subtilis sub sp. & BCT-7112(T) & СР006863 & 98.54 & [29] \\
\hline
\end{tabular}

Table 9: List of the closely related strains for sample S-III D

\begin{tabular}{llllll}
\hline S. No. & Name of strain & Code & Accession no. & Pairwise similarity \% & Reference \\
\hline 1 & Bacillus shackletonii & ATCC 14580(T) & AE017333 & 99.68 & {$[30]$} \\
2 & Bacillus sonorensis & NBRC 101234(T) & AYTN01000016 & 99.61 & {$[31]$} \\
3 & Bacillus aureus & 24K(T) & AJ831843 & 99.36 & {$[32]$} \\
4 & Bacillus toyonensis & GSS04(T) & KJ818278 & 99.01 & {$[33]$} \\
5 & Bacillus shackletonii & LMG 18435(T) & AJ250318 & 98.87 & {$[30]$} \\
\hline
\end{tabular}


Table 10: List of the closely related strains for sample S-IV C

\begin{tabular}{lllll}
\hline S. No. & Name of strain & Code & Accession no. & Pairwise similarity \% \\
\hline 1 & Bacillus subtilis sub sp. inaquosorum & KCTC13429(T) & AMXN01000021 & 99.72 \\
2 & Bacillus aureus & KCTC13622(T) & AYT001000043 & 99.64 \\
3 & Bacillus anthracis subsp. subtilis & NCIB3610(T) & ABQL01000001 & 99.51 \\
4 & Bacillus subtilis ub sp. spizizenii & NCIB3610(T) & CP002905 & 99.34 \\
5 & Bacillus toyonensis & DSM8802(T) & AM747812 & 99.32 \\
\hline
\end{tabular}

GC-MS study elaborated every bit of information about the compounds extracted from isolates, like molecular weight, RT time, boiling point, structural formula, linear formula, and IUPAC names were mentioned in fig. 2. Applications and medical significance of every compound were analyzed with chemical library [37]. GC-MS analysis of S-III C, S-III D and S-IV C active rich fractions possessing four, three and four antibacterial compounds respectively. The RT of the Peaks reveals the presence of different compounds. The area covered by the peaks is directly proportional to the amount of compound present in the solvent. The peaks were selected and compared with a standard which automatically generated the list of compounds were enlisted in fig. 2.

\section{PCR protocol}

Using below 16S rRNA Universal primers (table 11 and 12) gene fragment was amplified using MJ Research Peltier Thermal Cycler.

\begin{tabular}{|c|c|c|c|c|c|c|c|c|}
\hline S. No. & RT & $\begin{array}{l}\text { Name of the } \\
\text { compound }\end{array}$ & $\begin{array}{l}\text { Molecular } \\
\text { formula }\end{array}$ & $\begin{array}{l}\text { Molec } \\
\text { ular } \\
\text { weight }\end{array}$ & $\begin{array}{l}\text { Peak } \\
\text { area\% } \%\end{array}$ & Structure & $\begin{array}{l}\text { Nature of } \\
\text { compound }\end{array}$ & Activity \\
\hline 1 & 3.454 & $\begin{array}{l}\text { Hydroquinone-M } \\
\text { (2-HO-) P478 }\end{array}$ & $\mathrm{C} 6 \mathrm{H} 6 \mathrm{O} 3$ & 282 & 0.47 & 0 & $\begin{array}{l}\text { Aromatic } \\
\text { compounds }\end{array}$ & $\begin{array}{l}\text { Hypolipidemic, } \\
\text { Antimicrobial, } \\
\text { Anti-inflammatory, } \\
\text { Anti-tumor activities, } \\
\text { Inhibits retroviral reverse } \\
\text { transcriptase }\end{array}$ \\
\hline 2 & 9.608 & $\begin{array}{l}\text { Eicosane } \\
\text { P1379 }\end{array}$ & $\mathrm{C} 20 \mathrm{H} 42$ & 141 & 0.30 & & $\begin{array}{l}\text { Clear colorless } \\
\text { liquid }\end{array}$ & $\begin{array}{l}\text { Antibacterial, } \\
\text { Antifungal }\end{array}$ \\
\hline 3 & 12.983 & $\begin{array}{l}\text { Vinylbital } \\
\text { P916 }\end{array}$ & $\mathrm{C} 11 \mathrm{H} 16 \mathrm{~N} 2 \mathrm{O} 3$ & 224 & 25.15 & & $\begin{array}{l}\text { Heterocyclic } \\
\text { compounds }\end{array}$ & $\begin{array}{l}\text { Antibacterial, } \\
\text { Antifungal }\end{array}$ \\
\hline 4 & 13.977 & Palmitic acid & $\mathrm{C} 15 \mathrm{H} 30 \mathrm{O} 2$ & 242 & 0.57 & & $\begin{array}{l}\text { Fatty } \\
\text { acid (saturated) }\end{array}$ & $\begin{array}{l}\text { Inhibits phagocytosis, } \\
\text { Antibacterial }\end{array}$ \\
\hline 5 & 33.775 & $\begin{array}{l}\text { Myristic acid } \\
\text { P1035 }\end{array}$ & $\mathrm{C} 14 \mathrm{H} 28 \mathrm{O} 2$ & 228 & 0.25 & & $\begin{array}{l}\text { Colorless, } \\
\text { flammable gas }\end{array}$ & Antibacterial \\
\hline 6 & 46.172 & $\begin{array}{l}\text { PCPIP precursor } \\
\text { (methylpiperazine) } \\
\text { P334 }\end{array}$ & $\mathrm{C} 5 \mathrm{H} 12 \mathrm{~N} 2$ & 100 & 0.27 & & $\begin{array}{l}\text { Aliphatic } \\
\text { hydrocarbon }\end{array}$ & Antibacterial \\
\hline 7 & 28.357 & $\begin{array}{l}\text { Barbituric acid } \\
3 \mathrm{MEP} 707\end{array}$ & $\mathrm{C} 7 \mathrm{H} 10 \mathrm{~N} 2 \mathrm{O} 3$ & 170 & & & - & \\
\hline 8 & 26.250 & $\begin{array}{l}\text { Stearic acid } \\
\text { P1389 }\end{array}$ & $\mathrm{C} 18 \mathrm{H} 36 \mathrm{O} 2$ & 284 & 21.34 & & $\begin{array}{l}\text { Aliphatic } \\
\text { hydrocarbon }\end{array}$ & Antibacterial \\
\hline 9 & 16.730 & $\begin{array}{l}\text { Linoleic acid } \\
\text { MEP1454 }\end{array}$ & $\mathrm{C} 19 \mathrm{H} 34 \mathrm{O} 2$ & 294 & 5.97 & 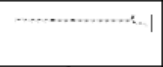 & $\begin{array}{l}\text { Aliphatic } \\
\text { hydrocarbon }\end{array}$ & Antibacterial \\
\hline 10 & 23.711 & $\begin{array}{l}\text { Diisooctylphthalate } \\
\text { P1828 }\end{array}$ & $\mathrm{C} 24 \mathrm{H} 38 \mathrm{O} 4$ & 390 & 1.12 & & $\begin{array}{l}\text { Aliphatic } \\
\text { hydrocarbon }\end{array}$ & Antibacterial \\
\hline 11 & 27.023 & $\begin{array}{l}\text { Diethylphthalate } \\
\text { P1004 }\end{array}$ & $\mathrm{C} 16 \mathrm{H} 22 \mathrm{O} 4$ & 222 & 0.92 & & $\begin{array}{l}\text { Aliphatic } \\
\text { hydrocarbon }\end{array}$ & Antibacterial \\
\hline
\end{tabular}

Fig. 2: GC-MS analysis of S-III C, S-III D and S-IV C active rich fractions possessing four, three and four antibacterial compounds respectively

Table 11: Primer details

\begin{tabular}{lll}
\hline Primer name & Sequence details & Number of base \\
\hline $27 \mathrm{~F}$ & AGAGTTTGATCMTGGCTCAG & 20 \\
$1492 \mathrm{R}$ & TACGGYTACCTTGTTACGACTT & 22 \\
\hline
\end{tabular}

Table 12: Sequencing primer details

\begin{tabular}{lll}
\hline Primer name & Sequence details & Number of base \\
\hline $785 \mathrm{~F}$ & GGATTAGATACCCTGGTA & 18 \\
$907 \mathrm{R}$ & CCGTCAATTCMTTTRAGTTT & 20 \\
\hline
\end{tabular}


The 16s r RNA sequence was blast using NCBI blast similarity search tool. The phylogeny analysis of our sequence with the closely related sequence of blast results was performed followed by multiple sequence alignment. The program MUSCLE 3.7 was used for multiple alignments of sequences [38]. The resulting aligned sequences were cured using the program G blocks $0.91 \mathrm{~b}$. Primer $785 \mathrm{~F}$ and $907 \mathrm{R}$ was used for sequence details and the number of the nucleotide sequence are shown in fig. $3 \mathrm{~A}, \mathrm{~B}$ and $\mathrm{C}$, the number of base are18 and 20 as shown in table 13 . This G blocks eliminates poorly aligned positions and divergent regions (removes alignment noise) [39]. Finally, the program PhyML 3.0aLRT was used for phylogeny analysis and HKY85 as Substitution model. PhyML was shown to be at least as accurate as other existing phylogeny programs using simulated data while being one order of magnitude faster. PhyML was shown to be at least as accurate as other existing phylogeny programs using simulated data, while being one order of magnitude faster. The program Tree Dyn 198.3 was used for tree rendering [40].

CGCTCTAATACATGCAGTCGAGCGGACCGACGGGAGCTTGCTCCCTTAGGTCAGCGGCGGACGGGTGAGTAA CACGTGGGTAACCTGCCTGTAAGACTGGGATAACTCCGGGAAACCGGGGCTAATACCGGATGCTTGATTGAAC CGCATGGTTCAATCATAAAGGTGGCTTTCAGCTACCACTTGCAGATGGACCCGCGGCGCATTAGCTAGTTGGT GAGGTAACGGCTCACCAAGGCGACGATGCGTAGCCGACCTGAGAGGGTGATCGGCCACACTGGGACTGAGAC ACGGCCCAGACTCCTACGGGAGGCAGCAGTAGGGAATCTTCCGCAATGGACGAAAGTCTGACGGAGCAACGC CGCGTGAGTGATGAAGGTTTTCGGATCGTAAAACTCTGTTGTTAGGGAAGAACAAGTACCGTTCGAATAGGGC GGTACCTTGACGGTACCTAACCAGAAAGCCACGGCTAACTACGTGCCAGCAGCCGCGGTAATACGTAGGTGG CAAGCGTTGTCCGGAATTATTGGGCGTAAAGCGCGCGCAGGCGGTTTCTTAAGTCTGATGTGAAAGCCCCCGG CTCAACCCGGGGGAGGGGTCATTGGAAACTGGGGAACTTGAGTGCAGAAGAGGAGAGTGGAATTTCCACGTG TAGCGGTGAAATGCGTAGAGATGTGGAGGAACACCAGTGGCGAARGGCGACTCTCCTGGTCTGTAACTGACG CTGAGGCGCGAAAGCGTGGGGAGCGAACAGGATTAGATACCCTGGTAGTCCACGCCGTAAACGATGAGTGCT AAGTGTTAGAGGGTTTCCGCCCTTTAGTGCTGCAGCAAACGCATTAAGCACTCCGCCTGGGGAGTACGGTCGC AAGACTGAAACTCAAAGGAATTGACGGGGGCCCGCACAAGCGGTGGAGCATGTGGTTTAATTCGAAGCAACG CGAAGAACCTTACCAGGTCTTGACATCCTCTGACAACCCTAGAGATAGGGCTTCCCCTTCGGGGGCAGAGTGA CAGGTGGTGCATGGTTGTCGTCAGCTCGTGTCGTGAGATGTTGGGTTAAGTCCCGCAACGAGCGCAACCCTTG ATCTTAGTTGCCAGCATTCAGTTGGGCACTCTAAGGTGACTGCCGGTGACAAACCGGAGGAAGGTGGGGATG ACGTCAAATCATCATGCCCCTTATGACCTGGGCTACACACGTGCTACAATGGGCAGAACAAAGGGCAGCGAA GCCGCGAGGCTAAGCCAATCCCACAAATCTGTTCTCAGTTCGGATCGCAGTCTGCAACTCGACTGCGTGAAGC TGGAATCGCTAGTAATCGCGGATCAGCATGCCGCGGTGAATACGTTCCCGGGCCTTGTACACACCGCCCGTCA CACCACGAGAGTTTGTAACACCCGAAGTCGGTGAGGTAACCTTTGGAGCCAGCCGCCGATGGTGAACCCA

A

TGCCTATACATGCAGTCGAGCGAATGGATTAAGAGCTTGCTCTTATGAAGTTAGCGGCGGACGGGTGAGTAAC ACGTGGGTAACCTGCCCATAAGACTGGGATAACTCCGGGAAACCGGGGCTAATACCGGATAACATTTTGAAC CGCATGGTTCGAAATTGAAAGGCGGCTTCGGCTGTCACTTATGGATGGACCCGCGTCGCATTAGCTAGTTGGT GAGGTAACGGCTCACCAAGGCAACGATGCGTAGCCGACCTGAGAGGGTGATCGGCCACACTGGGACTGAGAC ACGGCCCAGACTCCTACGGGAGGCAGCAGTAGGGAATCTTCCGCAATGGACGAAAGTCTGACGGAGCAACGC CGCGTGAGTGATGAAGGCTTTCGCCTCGTAAAACTCTGTTGTTAGGGAAGAACAAGTGCTAGTTGAATAAGCT GGCACCTTGACGGTACCTAACCAGAAAGCCACGGCTAACTACGTGCCAGCAGCCGCGGTAATACGTAGGTGG CAAGCGTTATCCGGAATTATTGGGCGTAAAGCGCGCGCAGGTGGTTTCTTAAGTCTGATGTGAAAGCCCACGG CTCAATTGCAGAGGGTCATTGGAAACTGGGAGACTTGAGTGCAGAAGAGGAAAGTGGAATTCCATGTGTAGC GGTGAAATGCGTAGAGATATGGAGGAACACCAGTGGCGAAGGCGACTTTCTGGTCTGTAACTGACACTGAGG CGCGAAAGCGTGGGGAGCAAACAGGATTAGATACCCTGGTAGTCCACGCCGTAAACGATGAGTGCTAGATGT TAGAGGGTTTCCGCCCTTTAGTGCTGAAGTTAACGCATTAAGCACTCCGCCTGGGGAGTACGGCCGCAAGGCT GAAACTCAAAGGAATTGACGGGGGCCCGCACAAGCGGTGGAGCATGTGGTTTAATTCGAAGCAACGCGAAGA ACCTTACCAGGTCTTGACATCCTCTGAAAACCCTAGAGATAGGGCTTCTCCTTCGGGAGCAGAGTGACAGGTG GTGCATGGTTGTCGTCAGCTCGTGTCGTGAGATGTTGGGTTAAGTCCCGCAACGAGCGCAACCCTTGATCTTA GTTGCCATCATTAAGTTGGGCACTCTAAGGTGACTGCCGGTGACAAACCGGAGGAAGGTGGGGATGACGTCA AATCATCATGCCCCTTATGACCTGGGCTACACACGTGCTACAATGGACGGTACAAAGAGCTGCAAGACCGCGA GGTGGAGCTAATCTCATAAAACCGTTCTCAGTTCGGATTGTAGCGTGCAACTCGCCTACATGAAGCTGGAATC GCTAGTAATCGCGGATCAGCATGCCGCGGTGAATACGTTCCCGGGCCTTGTACACACCGCCCGT

\section{B}

GGCGGACGGGTGAGTAACACGTGGGTAACCTGCCTGTAAGACTGGGATAACTCCGGGAAACCGGGGCTAATA CCGGATGGTTGTTTGAACCGCATGGTTCAAACATAAAAGGTGGCTTCGGCTACCACTTACAGATGGACCCGCG GCGCATTAGCTAGTTGGTGAGGTAACGGCTCACCAAGGCAACGATGCGTAGCCGACCTGAGAGGGTGATCGG CCACACTGGGACTGAGACACGGCCCAGACTCCTACGGGAGGCAGCAGTAGGGAATCTTCCGCAATGGACGAA AGTCTGACGGAGCAACGCCGCGTGAGTGATGAAGGTTTTCGGATCGTAAAGCTCTGTTGTTAGGGAAGAACA AGTACCGTTCGAATAGGGCGGTACCTTGACGGTACCTAACCAGAAAGCCACGGCTAACTACGTGCCAGCAGC CGCGGTAATACGTAGGTGGCAAGCGTTGTCCGGAATTATTGGGCGTAAAGGGCTCGCAGGCGGTTTCTTAAGT CTGATGTGAAAGCCCCCGGTTCAACCGGGGAGGGTCATTGGAAACTGGGGAACTTGAGTGCAGAAGAGGAGA GTGGAATTCCACGTGTAGCGGTGAAATGCGTAGAGATGTGGAGGAACACCAGTGGCGAAGGCGACTCTCTGG TCTGTAACTGACGCTGAGGAGCGAAAGCGTGGGGAGCGAACAGGATTAGATACCCTGGTAGTCCACGCCGTA AACGATGAGTGCTAAGTGTTAGGGGGTTTCCGCCCCTTAGTGCTGCAGCTAACGCATTAAGCACTCCGCCTGG GGAGTACGGTCGCAAGACTGAAACTCAAAGGAATTGACGGGGGCCCGCACAAGCGGTGGAGCGTGTGGTTTA ATTCGAAGCAACGCGAAGAACCTTACCAGGTCTTGACATCCTCTGACAATCCTAGAGATAGGACGTCCCCTTC GGGGGCAGAGTGACAGGTGGTGCATGGTTGTCGTCAGCTCGTGTCGTGAGATGTTGGGTTAAGTCCCGCAACG AGCGCAACCGTTGATCTTAGTTGCCAGCATTCAGTTGGGCACTCTAAGGTGACTGCCGGTGACAAACCGGAGG AAGGTGGGGATGACGTCAAATCATCATGCCCCTTATGACCTGGGCTACACACGTGCTACAATGGACAGAACA AAGGGCAGCGAAACCGCGAGGTTAAGCCAATCCCACAAATCTGTTCTCAGTTCGGATCGCAGTCTGCAACTC

Fig. 3: 16S rRNA sequencing of isolates, $A=S$-III C, B=S-III D, C=S-IV C 


\section{DISCUSSION}

Isolation of microorganisms from soil is the most convenient method. Soil contains millions of microorganisms per gram [41]. Soil from slum and hospital areas is the perfect place of the microbial vicinity. The selection of area was based on isolation of microbial community which can exist in extreme temperature of the arid region. These were isolated by warcup method and nutrient agar was used as basal media for cultivation of microbial population.

From the consortium of compounds detected, we focused on the ones which could be responsible for antibacterial, antimicrobial, and antifungal activities. S-III C produced four prominent compounds with potential antibacterial activity and incorporated in fig. 2 . Hydroquinone-M (2-HO-) P478 has anti-inflammatory and antitumor activity and inhibits retroviral reverse transcriptase activity. The source of isolation of this compound is mostly plants [42], and yeast [43]. Recently, its isolation was detected from halo tolerant Bacillus methylotrophicus by Jeyanthi and co-workers [44]. Similarly, eicosane P1379, vinylbital P916, palmitic acid compounds have antifungal activities. Palmitic acid was extracted from Terminalia glaucescens root bark [45]. Myristic acid P1035, PCPIP precursor (methyl piperazine) P334, barbituric acid 3MEP707, was detected in sample S-III D. There were two aspects common in all detected compounds: they are aliphatic hydrocarbons and possess antibacterial activities, which makes them responsible for the tool against nosocomial infection caused by pathogens. Some were found in a good amount per sample. Some compounds are the major constituents out of all biologically active compounds found in the extracts. Four of the compounds that showed antimicrobial and antibacterial activities, which were found in S-IV C sample, also have antibacterial, antiseptic and chemotherapeutic activities. All these facts make the isolate to fight nosocomial infection-causing pathogens. Stearic acid P1389 is colourless to faint yellow oily liquid, linoleic acid MEP1454 is aliphatic compound, and diisooctylphthalate P1828 is also of aliphatic nature. The majority of the compounds were isolated from either plant [42] or synthesised chemically. Thus, isolation from bacterial sources could be beneficial economically as well as ecologically. From the experimental results, it can be concluded that the detected compounds in active rich fractions of S-III C, S-III D and S-IV C were responsible for bioactivity against infection caused by nosocomial pathogens.

\section{CONCLUSION}

The main aim behind the present piece of research work is to isolate the strains from arid soil of Rajasthan having antimicrobial potentials to cure nosocomial infections and produce the antibiotics in bulk so that in future these microbes can be used as chemical factories. All the four areas were selected on the basis of contamination and more prone sites of infections. Total 29 isolated strains were tested for biochemical screening followed biological testing. The study was narrowed down to selected three strains SIIIC, S-IIID and S-IVC. These strains withstand the heat of fifty degrees in summer and two degree in winter, proving the diverse type of genetic constitution. Further characterization of such strains showed a close resemblance to Bacillus strains. This proved that the isolated microbial flora was not infectious, so can be safely used for isolation of novel metabolites and can work as chemical factories for the production of bioactive compounds. This study not only proves that Bacillus species is a future candidate for antimicrobial substances but also can work as a chemical factory for the production of the huge amount of drug candidates with simple modifications.

\section{ACKNOWLEDGEMENT}

The authors acknowledged the Vice Chairman, JECRC University Jaipur for providing JRF and S. P. Biotech, Jaipur for providing infrastructure for carrying out research work. Special mention of thanks for GC-MS analysis which was performed at Advanced Instrumentation Research Facility (AIRF) School of Physical Sciences (SPS), Jawaharlal Nehru University, New Delhi.

\section{CONFLICT OF INTERESTS}

There is no conflict of interest

\section{REFERENCES}

1. Singh S, Chakravarthy M, Sengupta S, Munshi N, Jose T, Chaya V. Analysis of a multi-centric pooled healthcare-associated infection data from India: New insights. J Nat Accred Board Hosp Healthcare Providers 2014;1 Suppl 2:39-43.

2. Kamat U, Ferreira A, Savio R, Motghare D. Antimicrobial resistance among nosocomial isolates in a teaching hospital in Goa. Indian J Community Med 2008;33:89-92.

3. Sharma G, Dang S, Gupta S, Gabrani R. Identification and molecular characterization of bacteria having antimicrobial and antibiofilm activity. Int J Pharm Pharm Sci 2016;8:111.

4. Mathai E, Kaufmann ME, Richard VS, John G, Brahmadathan KN. Typing of Acinetobacter baumannii isolated from hospitalacquired respiratory infections in a tertiary care centre in southern India. J Hosp Infect 2001;47 Suppl 2:159-62.

5. Sahni V, Agarwal SK, Singh NP, Anuradha S, Sikdar S, Wadhwa $A$, et al. Candidemia-an under-recognized nosocomial infection in Indian hospitals. J Assoc Physicians India 2005;53:607-11.

6. Demain AL, Fang A. The natural functions of SMs. In History of Modern Biotechnology I: Springer Berlin Heidelberg; 2000. p. 1-39.

7. Berdy J. Bioactive microbial metabolites. J Anti biol 2005;58 Suppl 1:1-26.

8. Bibb MJ. Regulation of secondary metabolism in Streptomycetes. Curr Opin Microbiol 2005;8 Suppl 2:208-15.

9. Lamichhane B. Antibiotic resistance patterns of gram negative isolates in a tertiary care hospital of Nepal. Asian J Pharm Clin Res 2014;7 Suppl 3:30-3.

10. Siddhardha B. Studies on the isolation, characterization and bioevaluation of SMs from Aspergillus funiculosus, Aspergillus gorakhpurensis and Curvulariaoryzae. Ph. D dissertation, Jawaharlal Nehru technological University; 2010.

11. Davies, Davies D. Origins and evolution of antibiotic resistance. Microbiol Mol Biol Rev 2010;74 Suppl 3:417-33.

12. Kumari P, Kumar A, Somasundaram ST. Identification of genes/enzymes responsible for antibiotic resistance in Vibrio alginolyticus strain PTS 13. Int J Curr Pharm Res 2015;7:76-83.

13. Stein T. Bacillus subtilis antibiotics: structures, syntheses and specific functions. Mol Microbiol 2005;56:845-57.

14. Bizani D, Motta AS, Morrissy JA, Terra R, Souto AA, Brandelli A. Antibacterial activity of cerein $8 \mathrm{~A}$, a bacteriocin-like peptide produced by Bacillus cereus. Int Microbiol 2010;8:125-31.

15. Xie J, Zhang R, Shang C, Guo Y. Isolation and characterization of a bacteriocin produced by an isolated Bacillus subtilis LFB112 that exhibits antimicrobial activity against domestic animal pathogens. Afr J Biotechnol 2009;8:5611-9.

16. Teixeira ML, Dalla RA, Brandelli A. Characterization of an antimicrobial peptide produced by Bacillus subtilis subsp. spizezinii showing inhibitory activity towards Haemophilusparasuis. Microbiology 2013;159:980-8.

17. Magaldi S, Mata-Essayag S, De Capriles CH, Perez C, Colella MT, Olaizola C, et al. Well diffusion for antifungal susceptibility testing. Int J Infect Dis 2004;8 Suppl 1:39-45.

18. Saadoun I, Wahiby L, Ababneh Q, Jaradat Z, Massadeh M, AlMomani F. Recovery of soil Streptomycetes from arid habitats in Jordan and their potential to inhibit multidrug resistant Pseudomonas aeruginosa pathogens. World J Microb Biot 2008;24:157-62.

19. Abussaud MJ, Alanagreh L, Elteen KA. Isolation, characterization and antimicrobial activity of Streptomyces strains from hot spring areas in the northern part of Jordan. Afr J Biotechnol 2013;12:7124-32.

20. Mandenius CF, Björkman M. Scale-up of cell bioreactors using biomechatronic design. Biotechnol J 2012;7:1026-39.

21. Pedersen-Bjergaard S, Rasmussen KE, Halvorsen TG. Liquidliquid extraction procedures for sample enrichment in capillary zone electrophoresis. J Chromatography 2000;902 Suppl 1:91105.

22. Balouiri Mounyr, Moulay Sadiki, Saad Koraichi. IBN souda methods for in vitro evaluating antimicrobial activity: a review. J Pharm Anal 2016;6:71-9.

23. Sahin N, Ugur A. Investigation of the antimicrobial activity of some Streptomyces isolates. Turk J Biol 2003;27:73-8. 
24. Verma B, Kumar P, Dhanasekaran D, Babalola 00, Banakar SP. Gas chromatography-mass spectrometry analysis and antibacterial activity of bluish green pigment from Pseudomonas sp. JJTBVK (KF836502). Braz Arch Biol Technol 2015;58 Suppl 4:628-35.

25. Kim OS, Cho YJ, Lee K, Yoon SH, Kim M, Na H, et al. Introducing EzTaxon-e: a prokaryotic 16S rRNA gene sequence database with phylotypes that represent uncultured species. Int J Syst Evol Microbiol 2012;62:716-21.

26. Frankland GC, Frankland PF. Studies on some new microorganisms obtained from air. Philos Trans $R$ Soc $B$ 1887; 178:257-87.

27. Claus DR. Genus bacillus cohn 1872. Bergey's manual of systematic bacteriology. $2^{\text {nd }}$ ed.; 1986. p. 1105-39.

28. Berliner E. Über die schlaffsucht der mehlmottenraupe (Ephestiakühniella Zell.) und ihren Erreger Bacillus thuringiensis n. sp. Z Angew Entomol 1915;2:29-56.

29. Olaya-Abril A, Jiménez-Munguía I, Gómez-Gascón L, RodríguezOrtega MJ. Surfomics: shaving live organisms for a fast proteomic identification of surface proteins. J Proteomics 2014;97:164-76.

30. Logan NA, Lebbe L, Verhelst A, Goris J, Forsyth G, RodríguezDíaz M, et al. Bacillus shackletonii sp. nov., from volcanic soil on Candlemas Island, South Sandwich archipelago. Int J Syst Evol Microbiol 2004;54 Suppl 2:373-6.

31. Palmisano MM, Nakamura LK, Duncan KE, Istock CA, Cohan FM. Bacillus sonorensis sp. nov., a close relative of Bacillus licheniformis, isolated from soil in the sonoran desert, Arizona. Int J Syst Evol Microbiol 2001;51:1671-9.

32. Shivaji S, Chaturvedi P, Suresh K, Reddy GS, Dutt CB, Wainwright M, et al. Bacillus aureus sp. nov., Bacillus aerophilus sp. nov., Bacillus stratosphericus sp. nov. and Bacillus altitudinis sp. nov., isolated from cryogenic tubes used for collecting air samples from high altitudes. Int J Syst Evol Microbiol 2006;56:1465-73.

33. Jiménez G, Urdiain M, Cifuentes A, López-López A, Blanch AR, Tamames J, et al. Description of Bacillus toyonensis sp. nov., a novel species of the Bacillus cereus group, and pairwise genome comparisons of the species of the group by means of ANI calculations. Syst Appl Microbiol 2013;36:383-91.

34. Rooney AP, Price NP, Ehrhardt C, Swezey JL, Bannan JD. Phylogeny and molecular taxonomy of the Bacillus subtilis species complex and description of Bacillus subtilis subsp. inaquosorum subsp. nov. Int J Syst Evol Microbiol 2009; 59:2429-36.
35. Gatson JW, Benz BF, Chandrasekaran C, Satomi M, Venkateswaran K, Hart ME. Bacillus tequilensis sp. nov., isolated from a 2000-year-old Mexican shaft-tomb, is closely related to Bacillus subtilis. Int J Syst Evol Microbiol 2006;56:1475-84.

36. Nakamura LK, Roberts MS, Cohan FM. Relationship of Bacillus subtilis clades associated with strains 168 and W 23:a proposal for Bacillus subtilis subsp. subtilis subsp. nov. and Bacillus subtilis subsp. spizizenii subsp. nov. Int J Syst Bacteriol 1999;49:1211-5.

37. Ceylan O, Okmen G, Ugur A. Isolation of soil streptomyces as source antibiotics active against antibiotic resistant bacteria. Eur-Asia J Biol Sci 2008;2:73-82.

38. Edgar RC. MUSCLE: multiple sequence alignment with high accuracy and high throughput. Nucleic Acids Res 2004;32:1792-7.

39. Talavera G, Castresana J. Improvement of phylogenies after removing divergent and ambiguously aligned blocks from protein sequence alignments. Syst Biol 2007;56:564-77.

40. Dereeper A, Guignon V, Blanc G, Audic S, Buffet S, Chevenet F, et al. Phylogeny. fr: robust phylogenetic analysis for the nonspecialist. Nucleic Acids Res 2008;36:465-9.

41. Eichorst SA, Breznak JA, Schmidt TM. Isolation and characterization of soil bacteria that define Terriglobus gen. nov., in the phylum Acidobacteria. Appl Environ Microbiol 2007;73:2708-17.

42. Kirk RE, Othmer DF. Encyclopedia of chemical technology. 2nd ed. New York: The Interscience Encyclopedia, Inc; 1953.

43. Kohama Y, T Teramoto, Y Kayamori, M Itoh, T Mimura, An Inada, et al. Nakanishi isolation and identification of hydroquinone in baker's yeast. Agric Biol Chem 1990;54 Suppl 11:3051-2.

44. Jeyanthi V, Anbu P, Vairamani M, Velusamy P. Isolation of hydroquinone (benzene-1, 4-diol) metabolite from halotolerant Bacillus methylotrophicus MHC10 and its inhibitory activity towards bacterial pathogens. Bioprocess Biosyst Eng 2016;39 Suppl 3:429-39.

45. Bulama JS, Dangoggo SM, Halilu ME, Tsafe AI, Hassan SW. Isolation and characterization of palmitic acid from ethyl acetate extract of root bark of Terminalia glaucescens. J Chem Mater Res 2014;6 Suppl 12:140-4.

\section{How to cite this article}

- Abhishek Sharma, Ekta Menghani. Microorganisms as chemical factories for isolation of metabolomes from the mesophilic soil. Int J Pharm Pharm Sci 2017;9(4):121-128. 